\title{
Combined Photodynamic and Radiotherapy Synergistic Effect in Cancer Treatment
}

\author{
Fatma Yurt* and Ayça Tunçel \\ Department of Nuclear Applications, Ege University, Institute of Nuclear Science, Turkey \\ *Corresponding author: Fatma Yurt, Department of Nuclear Applications, Institute of Nuclear Science, Ege University, Bornova, 35100, Izmir, Turkey
}

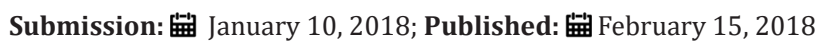

\begin{abstract}
This review aims to increase the success rate in the treatment of cancer when both photodynamic therapy and radiotherapy are used together as a combined therapy and it is aimed to inform this direction.
\end{abstract}

Keywords: Photodynamic therapy; Cancer; Radiotherapy

Abbreviations: PS: Photosensitizer; PDT: Photodynamic therapy; ROS: Reactive Single Oxygen;UV: Ultraviolet; FRET: Fluorescence Resonance Energy; CT: Chemotherapy; IT: Immunotherapy; RT: Radiotherapy; SPECT: Single Photon Emission Computed Tomography; PET: Positron Emission Tomography;

\section{Introduction}

Photodynamic therapy (PDT) is a noninvasive method in cancer treatment. Nowadays, it has been used in clinical successfully to the treatment of skin, esophagus and lung cancer [1-3]. PDT occurs which a certain wavelength light is excited the photosensitizer (PS). As a result of this photo-excitation, reactive single oxygen (ROS) species form locally and cause cancer cell death [4-7]. When applied the light to PS is excitedfrom ground state to short live singlet state and then converted triplet state with long live. Triplet state of PS can produce ROS via two different photochemical reactions; type I and type II. In Type I PS in the triplet state reacts with water or biomolecules and then generated free radicals, superoxides and peroxides. In type II, singlet oxygen which is very reactive occurs from reaction the triplet state and molecular oxygen in the tissue oxygen.

In PDT of cancer, PDT effect of organic PSs (e.g., phthalocyanine [8-11] Porphyrin [12-13], chlorine [14-16], etc.) is carried out with Type II mechanism, On the other metal ion-centered PS (Zn, Cu etc.) mechanism is Type I in the PDT [17] and semiconductors (e.g. CdSe [18], $\mathrm{ZnO}[19]$ etc.) and photocatalysts (e.g. $\mathrm{TiO}_{2}[19], \mathrm{W}_{18} \mathrm{O}_{49}$ [20] etc.) have been successfully used in treatment of specific tumors.

The excitation wavelength of most PSs is in the ultraviolet (UV) and visible (vis) region $(\lambda \approx 400-700 \mathrm{~nm})$ [21]. When wavelength of light is below $800 \mathrm{~nm}$, tissue penetration is poor [22]. It is possible to increase the success of PDT accessing internal organs or tumors inhypodermicby using optical fibers via endoscopy [2324]. Moreover, owing to nanotechnology, in PDT systems, instead of direct light excitation of PSs, their indirect light excitations are possible [25]. For example, some photovoltaic NPs transfer Fluorescence Resonance Energy (FRET) to PS. Thus traditional PDT's tissue penetration restriction may be able to overcome and efficiency of the method increases [26-29].

Although, the efficacy of PDT is increased by different methods, there are many new and successful studies with combination of chemotherapy (CT), immunotherapy (IT) and radiotherapy (RT). There is a synergetic effect enhanced by the combined treatment which improves the success of each method positively. As previously mentioned, in PDT ROS by photochemical reaction generates to destroy cancer cells and cause DNA damage [30]. Also, in RT free radicals are generated via high-energy ionizing radiation and create DNA damage.Consequently the main goal of both methods is to damage DNA.There is synergistic interaction between these two methods that may cause permanent cell death [31].

Currently, in cancer treatment radionuclides, radiolabeled compounds, X-ray, electron beams which can be classified as external and internal radiotherapy and these radiation sources widely used in clinical [32]. In RT the growth of cancerous cells is kept under control with ionizing radiation effect. To preventof the recurrence of cancer before and after surgical removal of primer malign tumors, RT is used in the clinic.In monitoring of therapy response, radionuclide-based imaging techniques; Single Photon Emission Computed Tomography (SPECT) and Positron Emission Tomography (PET) are commonly used [33-35]. In addition, these techniquesalso provide the detection of deep-seated tumors 
and inform about the pathophysiology and pathobiochemical processes of the tumor.In literature apoptosis mechanism was carried out by using radiotracer and PS (64Cu-DOTA-biotinZnPcS2 and AlPcS2) in combined PDT and RT [36], On the other hand, nuclear imaging and PDT is possible with combined some radioisotope/radiopharmaceutics and PSfortargeting metabolic actions such as hypoxia ( $\left.{ }^{123} \mathrm{I}-\mathrm{IAZA} /{ }^{99 \mathrm{~m}} \mathrm{Tc}-\mathrm{HMPAO}-\mathrm{PII}\right)$ [37-38], vascular damage $\left({ }^{99 \mathrm{~m}} \mathrm{Tc}-\mathrm{HMPAO}-\mathrm{PII}\right)$ [39], proliferation $\left({ }^{18} \mathrm{~F}-\mathrm{FL}-\right.$ ATP-S $_{10}(\mathrm{Na})$ ) [40], membrane renewal $\left({ }^{11} \mathrm{C}\right.$-Choline-Pc4) [41] or mitochondrial resistance and glucose metabolism (Bolus 18F-FDGPII and AlPcS/Bolus ${ }^{18} \mathrm{~F}$-FDG-ADMP06/Bolus ${ }^{18} \mathrm{~F}$-FDG-Anti-CD104isothiocyanato porphyrin conjugate) [42-44]. In another PDT/RT combined treatment when NIR and X-ray on indocyanine green were applied during cancer treatmentsome favorable results were obtained. For instance the combined method, viability rate of MCF7 cells was determinedas $26 \%$ when only PDT was applied. When they were exposed only RT; the viability rate of MCF-7 cells was $84 \%$. Whereas the viability rate of MCF-7 cells was found as $3 \%$ when both combined methods were used. It is observed that the combined treatment has favorable synergistic effect [45]. Besides the effective results of the combined treatmentin cancer treatment, it is important that the side effects of light intensity and X-ray dose are minimized. In summary, multiple approaches for PDT/ RT combined therapy have shown success synergistic effect on the treatment of cancer [46-50].

\section{References}

1. Allison RR, Sibata CH (2010) Oncologic photodynamic therapy photosensitizers: a clinical review. Photodiagnosis Photodyn Ther 7(2): 61-75.

2. Fan W, Huang P, Chen X (2016) Overcoming the Achilles heel of photodynamic therapy. Chem Soc Rev 45: 6488-6519.

3. Sawamura T, Tanaka T, Ishige H, Iizuka M, Murayama Y, et al. (2015) The Effect of Coatings on the Affinity of Lanthanide Nanoparticles to MKN45 and HeLa Cancer Cells and Improvement in Photodynamic Therapy Efficiency. Int J Mol Sci 16(9): 22415-22424.

4. Castano AP, Demidova TN, Hamblin MR (2005) Mechanisms in photodynamic therapy: Part three-Photosensitizer pharmacokinetics, biodistribution, tumor localization and modes of tumor destruction. Photodiagnosis Photodyn Ther 2(2): 91-106

5. Voon SH, Kiew LV, Lee HB, Lim SH, Noordin MI, et al. (2014) In vivo studies of nanostructure-based photosensitizers for photodynamic cancer therapy. Small 10(24): 4993-5013.

6. Lu K, He C, Lin W (2015) A Chlorin-Based Nanoscale Metal-Organic Framework for Photodynamic Therapy of Colon Cancers. J Am Chem Soc 137(24): 7600-7603.

7. Huang P, Lin J, Wang X, Wang Z, Zhang C, et al. (2012) Light-triggered theranostics based on photosensitizer-conjugated carbon dots for simultaneous enhanced-fluorescence imaging and photodynamic therapy. Adv Mater 24(37): 5104-5110.

8. Ocakoglu K, Er O, Ersoz OA, Lambrecht FY, Ince M, et al. (2016) Evaluation of nuclear imaging potential and photodynamic therapy efficacy of symmetrical and asymmetrical zinc phthalocyanines. J Drug Del Sci Technol 33: 164-169.

9. Yurt Lambrecht F, Ocakoglu K, Er O, Ince M, Gunduz C, et al. (2016) Nuclear imaging potential and in vitro photodynamic activity of symmetrical and asymmetrical zinc phthalocyanines. J Labelled Compd $\operatorname{Rad}$ 59(5): 221-227.

10. Ince M, Er O, Ocakoglu K, Lambrecht FY, Colak SG, et al. (2016) Investigation of In vitro PDT Activities and In vivo Biopotential of Zinc Phthalocyanines Using 131I Radioisotope. Chemical Biology \& Drug Design 87(2): 224-232.

11. Zhao Z, Han Y, Lin C, Hu D, Wang F, et al. (2012) Multifunctional core-shell up converting nano particles for imaging and photodynamic therapy of liver cancer cells. Chem Asian J 7(4): 830-837.

12. O'Connor AE, Gallagher WM, Byrne AT (2009) Porphyrin and nonporphyrin photosensitizers in oncology: preclinical and clinical advances in photodynamic therapy. Photochem Photobiol 85(5): 10531074

13. Pushpan SK, Venkatraman S, Anand VG, Sankar J, Parmeswaran D, et al. (2002) Porphyrins in photodynamic therapy - a search for ideal photosensitizers. Curr Med Chem Anticancer Agents 2(2): 187-207.

14. Yu Q Rodriguez EM, Naccache R, Forgione P, Lamoureux G, et al. (2014) Chemical modification of temoporfin--a second generation photosensitizer activated using upconverting nanoparticles for singlet oxygen generation. Chem Commun (Camb) 50: 12150-12153.

15. Ocakoglu K, Er O, Kiyak G, Lambrecht FY, Gunduz C, et al. (2015) 131I-Zn-Chlorophyll derivative photosensitizer for tumor imaging and photodynamic therapy. Int J Pharm 493(1-2): 96-101.

16. Srivatsan A, Pera P, Joshi P, Wang Y, Missert JR, et al. (2015) Effect of chirality on cellular uptake, imaging and photodynamic therapy of photosensitizers derived from chlorophyll-a. Bioorganic \& medicinal chemistry 23(13): 3603-3617.

17. Samia AC, Chen X, Burda C (2003) Semiconductor Quantum Dots for Photodynamic Therapy. J Am Chem Soc 125(51): 15736-15737.

18. Kang Z, Yan X, Zhao L, Liao Q, Zhao K, et al. (2015) Gold nanoparticle/ $\mathrm{ZnO}$ nanorod hybrids for enhanced reactive oxygen species generation and photodynamic therapy. Nano Research 8(6): 2004-2014.

19. Jańczyk A, Krakowska E, Stochel G, Macyk W (2006) Singlet Oxygen Photogeneration at Surface Modified Titanium Dioxide. J Am Chem Soc 128(49): 15574-15575

20. Kalluru P, Vankayala R, Chiang CS, Hwang KC (2013) Photosensitization of singlet oxygen and in vivo photodynamic therapeutic effects mediated by PEGylated W(18) O (49) nanowires. Angew Chem Int Ed Engl 52(47): $12332-12336$

21. Plaetzer K, Krammer B, Berlanda J, Berr F, Kiesslich T (2009) Photophysics and photochemistry of photodynamic therapy: fundamental aspects. Lasers Med Sci 24(2): 259-268.

22. Hu J, Tang Y, Elmenoufy AH, Xu H, Cheng Z, et al. (2015) NanocompositeBased Photodynamic Therapy Strategies for Deep Tumor Treatment. Small 11(44): 5860-5887.

23. Bechet D, Mordon SR, Guillemin F, Barberi-Heyob MA (2014) Photodynamic therapy of malignant brain tumours: a complementary approach to conventional therapies. Cancer Treat Rev 40(2): 229-241.

24. Qian HS, Guo HC, Ho PC, Mahendran R, Zhang Y (2009) Mesoporoussilica-coated up-conversion fluorescent nanoparticles for photodynamic therapy. Small 5(20): 2285-2290.

25. Hou B, Zheng B, Gong X, Wang H, Wang S, et al. (2015) A UCN@mSiO2@ cross-linked lipid with high steric stability as a NIR remote controlledrelease nanocarrier for photodynamic therapy. Journal of Materials Chemistry B 3(17): 3531-3540.

26. Punjabi A, Wu X, Tokatli-Apollon A, El-Rifai M, Lee H, et al. (2014) Amplifying the red-emission of upconverting nanoparticles for biocompatible clinically used prodrug-induced photodynamic therapy. ACS Nano 8(10): 10621-10630. 
27. Tang Y, Hu J, Elmenoufy AH, Yang X (2015) Highly Efficient FRET System Capable of Deep Photodynamic Therapy Established on X-ray Excited Mesoporous LaF3: Tb Scintillating Nanoparticles. ACS Appl Mater Interfaces 7(22): 12261-12269.

28. CHen H, Wang GD, Chuang YJ, Zhen Z, Chen X, et al. (2015) Nanoscintillator-mediated X-ray inducible photodynamic therapy for in vivo cancer treatment. Nano Lett 15(4): 2249-2256.

29. Ochsner M (1997) Photophysical and photobiological processes in the photodynamic therapy of tumours. J Photochem Photobiol B 39: 1-18

30. Juzenas P, Chen W, Sun YP, Coelho MA, Generalov R, et al. (2008) Quantum dots and nanoparticles for photodynamic and radiation therapies of cancer. Adv Drug Deliv Rev 60(15): 1600-1614.

31. Colasanti A, Kisslinger A, Quarto M, Riccio P (2004) Combined effects of radiotherapy and photodynamic therapy on an in vitro human prostate model. Acta biochimica Polonica 51(4): 1039-1046.

32. Garibotto V, Heinzer S, Vulliemoz S, Guignard R, Wissmeyer M, et al. (2013) Clinical applications of hybrid PET/MRI in neuroimaging. Clin Nucl Med 38(1): e13-e18.

33. Bailey DL, Willowson KP (2014) Quantitative SPECT/CT: SPECT joins PET as a quantitative imaging modality. Eur J Nucl Med Mol Imaging 41(Suppl 1): S17-S25.

34. Mariani G, Bruselli L, Kuwert T, Kim EE, Flotats A, et al. (2010) A review on the clinical uses of SPECT/CT. Eur J Nucl Med Mol Imaging 37(10): 1959-1985.

35. Strandberg S, Karlsson CT, Sundström T, Ögren M, Ögren M, et al. (2014) (11) C-acetate PET/CT in pre-therapeutic lymph node staging in highrisk prostate cancer patients and its influence on disease management - a retrospective study. EJNMMI Research 4(1): 55.

36. Cauchon N, Langlois R, Rousseau JA, Tessier G, Cadorette J, et al. (2007) PET imaging of apoptosis with 64Cu-labeled streptavidin following pretargeting of phosphatidylserine with biotinylated annexin-V. Eur J Nucl Med Mol Imaging 34(2): 247-258.

37. Subbarayan M, Häfeli UO, Feyes DK, Unnithan J, Emancipator SN, et al. (2003) A simplified method for preparation of $99 \mathrm{mTc}-a n n e x i n \mathrm{~V}$ and its biologic evaluation for in vivo imaging of apoptosis after photodynamic therapy. J Nucl Med 44(4): 650-656.

38. Moore RB, Chapman JD, Mercer JR, Mannan RH, Wiebe LI, et al. (1993) Measurement of PDT-induced hypoxia in Dunning prostate tumors by iodine-123-iodoazomycin arabinoside. Journal of nuclear medicine: official publication, Society of Nuclear Medicine 34(3): 405-411.

39. Moore RB, Chapman JD, Mokrzanowski AD, Arnfield MR, McPhee MS,

Creative Commons Attribution 4.0

International License

For possible submission use the below is the URL et al. (1992) Non-invasive monitoring of photodynamic therapy with 99technetium HMPAO scintigraphy. British Journal of Cancer 65: 491.

40. Sugiyama M, Sakahara H, Sato K, Harada N, Fukumoto D, et al. (2004) Evaluation of $3^{\prime}$-Deoxy-3'-18F-Fluorothymidine for Monitoring Tumor Response to Radiotherapy and Photodynamic Therapy in Mice. J Nucl Med 45(10): 1754-1758.

41. Fei B, Wang H, Wu C, Chiu SM (2010) Choline PET for Monitoring Early Tumor Response to Photodynamic Therapy. J Nucl Med 51(1): 130-138.

42. Lapointe D, Brasseur N, Cadorette J, La Madeleine C, Rodrigue S, et al (1999) High-resolution PET imaging for in vivo monitoring of tumor response after photodynamic therapy in mice. J Nucl Med 40(5): 876882.

43. Byrne AT, O'Connor AE, Hall M, Murtagh J, O'Neill K, et al. (2009) Vascular-targeted photodynamic therapy with BF2-chelated TetraarylAzadipyrromethene agents: a multi-modality molecular imaging approach to therapeutic assessment. Br J Cancer 101(9): 1565-1573.

44. Smith K, Malatesti N, Cauchon N, Hunting D, Lecomte R, et al. (2011) Mono- and tri-cationic porphyrin-monoclonal antibody conjugates: photodynamic activity and mechanism of action. Immunology 132(2): 256-265.

45. Montazerabadi AR, Sazgarnia A, Bahreyni-Toosi MH, Ahmadi A Aledavood A (2012) The effects of combined treatment with ionizing radiation and indocyanine green-mediated photodynamic therapy on breast cancer cells. J Photochem Photobiol B 109: 42-49.

46. Liu J, Yang Y, Zhu W, Yi X, Dong Z, et al. (2016) Nanoscale metal-organic frameworks for combined photodynamic \& radiation therapy in cancer treatment. Biomaterials 97: 1-9.

47. Lim SH, Thivierge C, Nowak-Sliwinska P, Han J, van den Bergh H, et al. (2010) In Vitro and In Vivo Photocytotoxicity of Boron Dipyrromethene Derivatives for Photodynamic Therapy. J Med Chem 53(7): 2865-2874.

48. Qiao XF, Zhou JC, Xiao JW, Wang YF, Sun LD, et al. (2012) Triple-functional core-shell structured upconversion luminescent nanoparticles covalently grafted with photosensitizer for luminescent, magnetic resonance imaging and photodynamic therapy in vitro. Nanoscale 4(15): 4611-4623.

49. Takahashi J, Misawa M (2009) Characterization of Reactive Oxygen Species Generated by Protoporphyrin IX under X-ray Irradiation. Radiat Phys Chem 78(11): 889-898.

50. Zhang C, Zhao K, Bu W, Ni D, Liu Y, et al. (2015) Marriage of Scintillator and Semiconductor for Synchronous Radiotherapy and Deep Photodynamic Therapy with Diminished Oxygen Dependence. Angew Chem Int Ed Engl 54(6): 1770-1774.

\section{Your subsequent submission with Crimson Publishers} will attain the below benefits

- High-level peer review and editorial services

- Freely accessible online immediately upon publication

- Authors retain the copyright to their work

- Licensing it under a Creative Commons license

- Visibility through different online platforms

- Global attainment for your research

- Article availability in different formats (Pdf, E-pub, Full Text)

- Endless customer service

- Reasonable Membership services

- Reprints availability upon request

- One step article tracking system 